Figure. Predictors of Methotrexate Insufficient Response or Rapid Radiographic Progression in Patients with Early Rheumatoid Arthritis Receiving Methotrexate
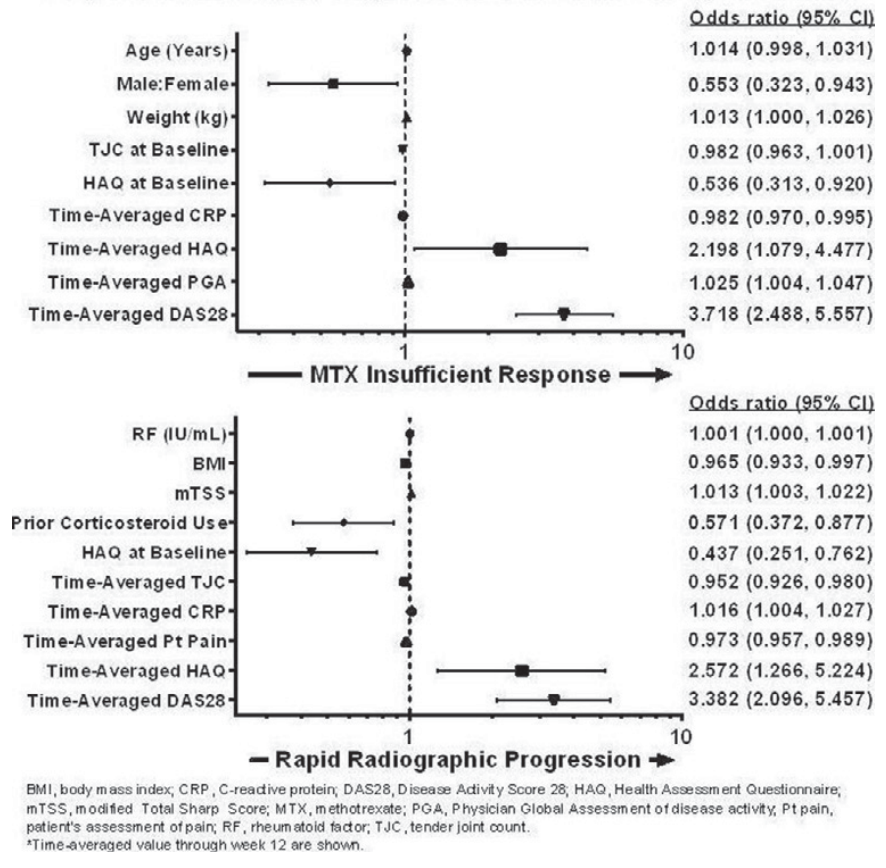

Disclosure of Interest: A. Kavanaugh Grant/research support from: AbbVie, Amgen, AstraZeneca, BMS, Celgene, Centocor-Janssen, Pfizer, Roche, and UCB, Consultant for: AbbVie, Amgen, AstraZeneca, BMS, Celgene, Centocor-Janssen, Pfizer, Roche, and UCB, Speakers bureau: AbbVie, Amgen, AstraZeneca, BMS, Celgene, Centocor-Janssen, Pfizer, Roche, and UCB, R. F. van Vollenhoven Grant/research support from: AbbVie, Amgen, BMS, GSK, Pfizer, Roche, and UCB, Consultant for: AbbVie, Biotest, BMS, Crescendo, GSK, Centocor-Janssen, Lilly, Merck, Pfizer, Roche, UCB, and Vertex, B. A. Wolfe Shareholder of: AbbVie, Employee of: AbbVie, S. Florentinus Shareholder of: AbbVie, Employee of: AbbVie, S. Chen Shareholder of: AbbVie, Employee of: AbbVie, J. L. Suboticki Shareholder of: AbbVie, Employee of: AbbVie, J. S. Smolen Grant/research support from: AbbVie, Consultant for: AbbVie, Speakers bureau: AbbVie DOI: 10.1136/annrheumdis-2017-eular.1892

\section{SAT0143 COMPARISON OF TREATMENT WITH GOLIMUMAB AND CERTOLIZUMAB-PEGOL IN ARTHRITIS- RESULTS FROM THE SOUTH SWEDISH ARTHRITIS TREATMENT GROUP (SSATG) REGISTER}

C. Roseman, E. Lindqvist, P. Geborek, M. Crnkic Kapetanovic. Section of Rheumatology, Lund University, Department of Clinical Sciences Lund, Skåne University Hospital, Lund, Sweden

Background: "Head to head" studies comparing the efficacy and tolerability of different TNF inhibitors are scarce, in particular the comparison between certolizumab pegol and golimumab.

Objectives: To compare the efficaciousness, drug survival and tolerability of certolizumab-pegol and golimumab in adult patients with establish arthritis (RA, JIA, SpA or unspecified polyarthritis) starting these treatments between February 2010 and December 2013 at out-patient unit at the Skåne University Hospital, Department of Rheumatology Lund/Malmö and two associated private rheumatology units.

Methods: All patients starting treatment with biologics were consecutively included in the South Swedish Arthritis Treatment Group (SSATG) register and regularly followed up according the standard protocol including: SJC/TJC, CRP, ESR, physicians global assessment of disease activity, patients' assessment of disease activity and pain (VAS global and VAS pain) and HAQ. Last follow up date was October 17th 2016. Kaplan-Meier survival analysis was used to estimate the drug survival. Possible predictors of drug survival were analysed using Cox regression model.

Results: In total, 352 patients (71\% women, mean age 51 years, mean disease duration 12 years, started these treatments during study period. Of these, 168 received golimumab and 184 certulizumab-pegol. Mean treatment time was 31 months (range 0-77). Percentage of patients with RA, SpA, JIA and unspecified arthritis were $58,4 \%, 16,4 \%, 5,7 \%$, and $19,5 \%$ respectively. Certolizumab-pegol was more used in RA ( $67 \%$ vs $49 \%$ ) and JIA ( $8 \%$ vs $2 \%$ ) while golimumab was more frequent among patients with $\operatorname{SpA}(21 \%$ and $12 \%)$ or PsA $(23 \%$ and 10 , respectively). Only $7 \%$ of golimumab and $10 \%$ of certulizumab-pegol patients received these drugs as first biologic treatment and approximately $50 \%$ of patients received these drugs as $\geq 3$. biological treatment.

In golimumab treated patients mean DAS28 decreased from 4,3 (baseline) to 3,3
(3 months); 2,8 (6 months) and 2,7 (12 months) but levelled off at 36 months follow up. Corresponding mean DAS28 levels in certulizumab-pegol treated patients were 4,6 (baseline); 3,2 (3 months); 2,8 (6 months) and 2,6 (12 months). The similar pattern was seen in changes in $\mathrm{HAQ}$ and $\mathrm{CDAl}$ over the study time. There were no statistically significant differences in DAS, HAQ or CDAI between treatments at any follow up visit. At the end of follow up 64 (38\%) of golimumab and 60 $(32 \%)$ of certulizumab-pegol patients remained on their treatment. No significant difference in drug survival was seen between the treatments (Figure). Patients with spondylartropathy had significantly better survival on golimumab compared to RA patients $(p=0,005)$ whicih remained after adjustment for age, gender, CRP, number of previous biologics and concomitnt methotrexate at baseline.

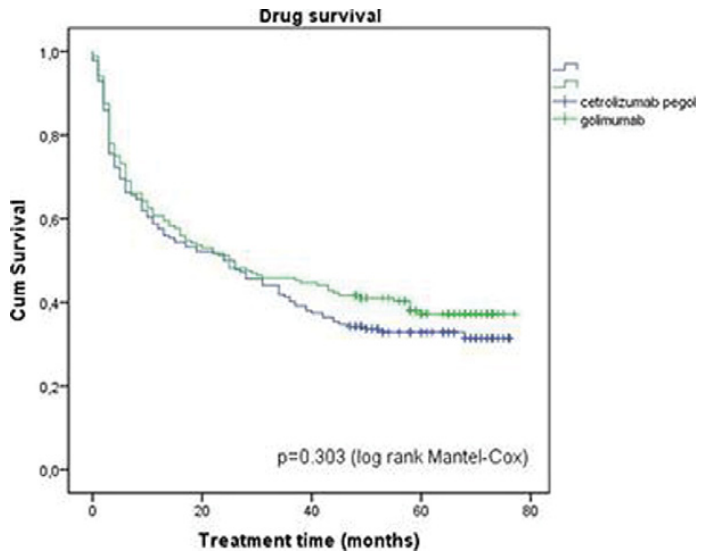

Conclusions: Spondylarthropathy including psoriatic arthritis was associated with better drug survival on golimunab compared to certolizumab pegol. No other significant differences in efficacy, tolerability or drug survival were seen between golimumab and certolizumab pegol in patients with established arthritis in daily clinical practice. Approximately one third of patients starting these treatments remained on treatment after 3 years.

Disclosure of Interest: None declared

DOI: 10.1136/annrheumdis-2017-eular.4818

\section{SAT0144 TUMOR NECROSIS FACTOR-ALPHA INHIBITORS AND PSYCHIATRIC SIDE EFFECTS: RESULTS FROM THE FRENCH PHARMACOVIGILANCE DATABASE}

C.M. Yelnik ${ }^{1}$, L. Gaboriau ${ }^{2}$, N. Petitpain ${ }^{3}$, H. Théophile ${ }^{4}$, C. Scalbert ${ }^{5}$, E. Delaporte ${ }^{5}$, S. Gautier ${ }^{2}$, M. Lambert ${ }^{1} .{ }^{1}$ Internal Medicine Department, University of Lille, UFR Medicine, Universitary Hospital Center of Lille; ${ }^{2}$ Regional Pharmacovigilance center of Hauts-de-France, Lille; ${ }^{3}$ Regional

Pharmacovigilance center of Lorraine, Nancy; ${ }^{4}$ Universitary Hospital Center of Bordeaux, Regional pharmacovigilance center of Bordeaux, Bordeaux;

${ }^{5}$ Dermatology department, University of Lille, UFR Medicine, Universitary Hospital Center of Lille, Lille, France

Background: Although Tumor Necosis Factor alpha (TNF- $\alpha$ ) is a major proinflammatory cytokine in the brain, potential psychiatric side effects of TNF- $\alpha$ inhibitors have been little investigated. Manic and psychotic disorders are not recognized as TNF- $\alpha$ inhibitors' side effects even though few reports of such complications have been reported.

Objectives: This study reports cases with psychiatric symptoms (in the spectrum of psychotic and manic disorders) that occur during treatment with tumor necrosis factor alpha (TNF- $\alpha$ ) inhibitors and aims to evaluate the role of these agents as causative factors.

Methods: We searched the French Pharmocovigilance Database for consecutive cases of positive psychiatric side effects reported during treatment with TNF- $\alpha$ inhibitors. Major psychiatric symptoms were defined, according to DSM-V, as mania and psychosis, and minor psychiatric symptoms as psychomotor agitation, euphoria, hallucinations, personality distortion, and increased libido. Each case had one major symptom or at least one minor symptom.

Results: Among 7912 consecutive cases of side effects registered in the database for TNF- $\alpha$ inhibitors, 184 reported psychiatric symptoms, and of these, 71 met inclusion criteria, whereas 113 met an exclusion criterion. Depression was the most frequent cause for exclusion. TNF- $\alpha$ inhibitors were the only medication suspected in 56 cases (79\%). The time between beginning TNF- $\alpha$ inhibitors and onset of symptoms varied from hours to months with a median time of 49 days $(\mathrm{IQR}=156)$; initial symptoms mostly worsened under treatment. TNF- $\alpha$ inhibitors were withdrawn in $42(61 \%)$ cases. The improvement of symptoms was significantly associated with treatment withdrawal ( $78 \%$ versus $22 \%, p=0.01$ ). Relapses occurred after rechallenge of TNF- $\alpha$ inhibitors in three of four patients. Conclusions: We report the first cohort of 71 cases with psychiatric symptoms in the spectrum of manic and psychotic disorders during treatment with TNF- $\alpha$ inhibitors. Our experience suggests that anti-TNF $\alpha$ therapy may cause manic or psychotic side effects.

Disclosure of Interest: None declared 
Table 1. Description of psychiatric symptoms registered in the database for TNF- $\alpha$ inhibitors

\begin{tabular}{lc}
\hline Characteristics & Patients (Total = 71) \\
\hline Major psychiatric symptoms: & $11(15 \%)$ \\
- Manic episode & $8(11 \%)$ \\
- Acute psychosis & $3(4 \%)$ \\
Minor psychiatric symptoms: & $60(85 \%)$ \\
- Anxiety/Nervousness & $10(14 \%) / 6(8 \%)$ \\
- Insomnia or decreased need for sleep & $31(44 \%)$ \\
- Psychomotor agitation/Aggressiveness & $6(8 \%) / 8(11 \%)$ \\
- Hallucinations & $7(10 \%)$ \\
- Libido exacerbation & $2(3 \%)$ \\
- Euphoria, grandiosity & $4(6 \%)$ \\
- Derealization, depersonalization & $3(4 \%)$ \\
Psychiatric side effect improved: & $45(63 \%)$ \\
- TNF- $\alpha$ Inhibitors withdrawn & $32(45 \%)$ \\
- TNF- $\alpha$ Inhibitors not withdrawn & $9(13 \%)$ \\
- Missing data & $4(6 \%)$ \\
Psychiatric side effect did not improved: & $16(22 \%)$ \\
- TNF- $\alpha$ Inhibitors withdrawn & $8(11 \%)$ \\
- TNF- $\alpha$ Inhibitors not withdrawn & $4(6 \%)$ \\
- Missing data & $3(4 \%)$ \\
Missing data improved/not improved & $10(14 \%)$ \\
\hline
\end{tabular}

DOI: 10.1136/annrheumdis-2017-eular.1610

\section{SAT0145 INFLUENCE OF BODY MASS INDEX (BMI) ON THE DISEASE INFLAMMATORY ACTIVITY AND TREATMENT REPONSE IN PATIENTS WITH RHEUMATOID ARTHRITIS}

A. Villalba Yllan ${ }^{1}$, V. Navarro Compan ${ }^{1}$, C. Plasencia Rodriguez ${ }^{1}$, D. Peiteado Lopez $^{1}$, G. Bonilla Hernan ${ }^{1}$, L. Nuño Nuño ${ }^{1}$, A. Martinez Feito ${ }^{2}$,

D. Pascual-Salcedo ${ }^{2}$, C. Diego ${ }^{2}$, A. Balsa Criado ${ }^{1} \cdot{ }^{1}$ Rheumatology;

${ }^{2}$ Immunology, Hospital Universitario la Paz, Madrid, Spain

Background: The use of biological therapy (BT) in rheumatoid arthritis (RA) has supposes a very important change in the disease's treatment and prognosis. Drugs like Anti-TNF $\alpha$ have proven unquestionable effectiveness. However, the lack or loss of such effectiveness over time raises the dilemma of what factors may influence it. There are studies that suggest the influence of BMI on the efficacy of these drugs and therefore on the control of the disease.

Objectives: To determine the influence of BMI on disease activity and response to treatment with infliximab (ifx) in patients with RA.

Methods: A retrospective observational study of a population of 76 patients with RA who received infliximab treatment, in a standard guideline of $3 \mathrm{mg} / \mathrm{kg}$, in our service between 2000 and 2016 inclusive. The BMI was classified for some sub-studies in four categories: low $(<18.5)$, normal $(=18.5-<25)$, overweight $(=25-<30)$ and obesity $(=30)$. Disease activity was determined by DAS28 at three times: at baseline, at 6 months and at the year of infliximab treatment; Response to treatment was assessed by deltaDAS28 and EULAR response at 6 months and 1 year of treatment. The EULAR response was classified into two categories: "yes" (DeltaDAS28 $>1.2$, or $>0.6$ and DAS28 $<5.1$ ) and "no" (DeltaDAS28 <.6, or $<5.1$ ). First, activity and response rates to treatment were compared in these four groups over the three periods. A regression analysis was then performed for BMI and both activity and response to treatment.

Results: Characteristics of the 76 patients included in the study when initiating IFX therapy were: $66(86.8 \%)$ were women, median (range) age $54(21-83)$ years, $77, \% \mathrm{RF}+, 81 \% \mathrm{ACPA}+$, disease duration $10,8(1,0-39,0)$ years, $59 \%$ with concomitant methotrexate and $55 \%$ with other DMARDs. Median (range) BMI was $25,5(16,7-40,2) \mathrm{kg} / \mathrm{m}^{2}$. According to BMI, patients with underweight, normal, overweight and obesity were $0(0,0 \%), 41(53,9 \%), 22(28,9 \%)$ and $13(17,2 \%)$, respectively. The association between BMI and disease activity (median DAS28 (p25-p75)) is shown in Table 1:

Table 1

\begin{tabular}{|c|c|c|c|}
\hline & Normal & Overweight & Obesity \\
\hline DAS28 bas & $5,63(4-84-6,30)$ & $5,44(4,45-6,73)$ & $6,25(4,42-7,07)$ \\
\hline DAS28 6m & $3,90(2,89-5-12)$ & $3,97(3,32-5,43)$ & $4,80(3,35-5,72)$ \\
\hline DAS28 1y & $3,91(2,89-5,01)$ & $3,69(2,97-5,29)$ & $4,48(2,70-5,87)$ \\
\hline
\end{tabular}

The association between BMI and treatment response (median deltaDAS28 (p25-p75) and EULAR response (\%)) is shown in Table 2:

\begin{tabular}{lcccc} 
Table 2 & \multicolumn{5}{c}{ Obesity } & $p$ \\
\hline DDAS28 & Normal & Overweight & & \\
$\Delta$ DAS28 0-6m & $1,72(0,84-2,77)$ & $1,39(0,38-2,49)$ & $0,77(0,40-1,59)$ & 0,2 \\
DAS28 0-1y & $1,56(0,81-2,74)$ & $1,77(, 092-2,92)$ & $1,20(0,73-1,90)$ & 0,2 \\
EULAR response 6m & 70,7 & 68,2 & 30,8 & 0,065 \\
EULAR response 1y & 61,0 & 54,5 & 61,5 & 0,065 \\
\hline
\end{tabular}

In the longitudinal analysis, a trending but not statistically significant relationship between adjusted BMI and DAS28 was observed at six month and at one year of treatment onset: $\beta: 0,051 ; 95 \% \mathrm{Cl}(-0,06$ to 0,109$)$ and $\beta: 0,037 ; 95 \% \mathrm{Cl}(-0,022$ to 0,097 )
Conclusions: BMI seems to influence, in a non significantly manner, in disease activity and in treatment response in RA treated with infliximab. Obesity BMI values are associated with increased activity and a lower response to this treatment than lower BMI values.

Disclosure of Interest: None declared

DOI: 10.1136/annrheumdis-2017-eular.4449

\section{SAT0146 RANDOMISED DOUBLE-BLIND STUDY SHOWS COMPARABLE LONG-TERM EFFICACY AND SAFETY BETWEEN RITUXIMAB BIOSIMILAR CT-P10 AND INNOVATOR RITUXIMAB IN PATIENTS WITH RHEUMATOID ARTHRITIS: 48-WEEK RESULTS}

C.-H. Suh ${ }^{1}$, E. Chalouhi El Khouri ${ }^{2}$, P. Miranda ${ }^{3}$, F. F Cons Molina ${ }^{4}$, P. Shesternya ${ }^{5}$, F. Medina-Rodriguez ${ }^{6}$, P. Wiland ${ }^{7}$, S. Jeka ${ }^{8}$,

J. Chavez-Corrales ${ }^{9}$, T. Linde ${ }^{10}$, P. Hrycaj ${ }^{11}$, I. Hospodarskyy ${ }^{12}$

M. Abello-Banfi ${ }^{13}$, J. Jaworski ${ }^{14}$, M. Piotrowski ${ }^{15}$, W. Park ${ }^{16}$, S.C. Shim ${ }^{17}$

S.J. Lee ${ }^{18}$, S.Y. Lee ${ }^{18}$, D.H. Yoo ${ }^{19} .{ }^{1}$ Ajou University School of Medicine, Suwon, Korea, Republic Of; ${ }^{2}$ Clinica Internacional, Lima, Peru; ${ }^{3}$ Centro de Estudios Reumatológicos, Santiago, Chile; ${ }^{4}$ Centro de Investigacion en Artritis y Osteoporosis, Mexicali, Mexico; ${ }^{5}$ KrasSMU, Krasnoyarsk, Russian Federation; ${ }^{6}$ Biologics Especializados SA, Mexico City, Mexico; ${ }^{7}$ Medical University, Wroclaw; ${ }^{8}$ 2nd University Hospital, CM UMK, Bydgoszcz, Poland; ${ }^{9}$ Clinica San Borja, Lima, Peru; ${ }^{10}$ Rheumatology Medical Center, Halle/Saale, Germany; ${ }^{11}$ Poznañ University of Medical Sciences, Poznañ, Poland; ${ }^{12}$ Ternopil Medical University, Ternopil, Ukraine; ${ }^{13}$ Centro Integral de Reumatologia del Caribe, Barranquilla, Colombia; ${ }^{14}$ Reumatika - Centrum Reumatologii, Warszawa;

${ }^{15}$ Medical University of Lublin, Lublin, Poland; ${ }^{16}$ IN-HA University, School of Medicine, Incheon; ${ }^{17}$ Chungnam National University Hospital, Daejeon;

${ }^{18}$ Celltrion, Inc., Incheon; ${ }^{19}$ Hanyang University Hospital for Rheumatic Diseases, Seoul, Korea, Republic Of

Background: In phase 1 trials (NCT01534884 and NCT01873443), pharmacokinetic equivalence of CT-P10, biosimilar of rituximab, to innovator rituximab (RTX) was demonstrated. In the phase 3 study, equivalence of PK and efficacy up to week 24 were achieved between CT-P10 and RTX (US and EU sourced) $)^{1,2}$.

Objectives: To investigate the long-term efficacy, pharmacodynamics, immunogenicity and safety of CT-P10 up to week 48.

Methods: Patients with rheumatoid arthritis were randomly assigned to CT-P10, US-RTX or EU-RTX, in combination with MTX. The patients received 2 treatment courses at Week 0 and 24, each consisting of 2 infusions of $1000 \mathrm{mg}$ study drug at 2-week interval.

Results: A total of 372 patients were randomised, and 330 patients completed the 2nd course treatment. DAS28 scores through Week 48 were comparable between CT-P10 and US/EU-RTX (Figure), as well as the proportion of ACR responses at Week 48 between the CT-P10 and combined rituximab groups; $81.3 \%$ and $79.8 \%$ for ACR $20,55.4 \%$ and $53.9 \%$ for ACR50, and $31.7 \%$ and $33.7 \%$ for ACR 70 , respectively.

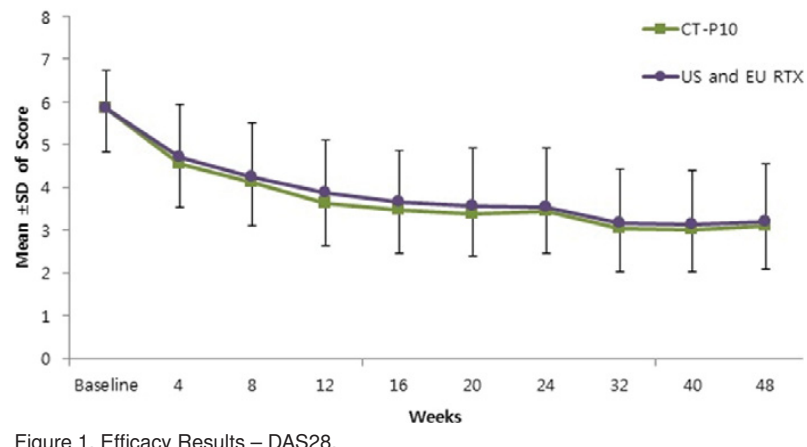

Figure 1. Efficacy Results - DAS28.

B-cell depletion was comparable from after the 1st infusion and up to Week 48. Number (\%) of patients with positive anti-drug antibodies in the CT-P10, US-RTX, and EU-RTX was 7 (4.9), 13 (9.4), and 5 (8.6), respectively at Week 48. The safety profile was also similar across groups (Table).

Table 1. Summary of Safety Profile [n (\%)]

\begin{tabular}{lcccc}
\hline & $\begin{array}{c}\text { CT-P10 } \\
(\mathrm{N}=161)\end{array}$ & $\begin{array}{c}\text { US-RTX } \\
(\mathrm{N}=151)\end{array}$ & $\begin{array}{c}\text { EU-RTX } \\
(\mathrm{N}=60)\end{array}$ & $\begin{array}{c}\text { Reference Products } \\
(\text { US-RTX + EU-RTX) } \\
(\mathrm{N}=211)\end{array}$ \\
\hline $\mathrm{AE}$ & $122(75.8)$ & $96(63.6)$ & $37(61.7)$ & $133(63.0)$ \\
Serious Adverse Event & $13(8.1)$ & $14(9.3)$ & $2(3.3)$ & $16(7.6)$ \\
Infection & $61(37.9)$ & $53(35.1)$ & $17(28.3)$ & $70(33.2)$ \\
Serious infection & $2(1.2)$ & $3(2.0)$ & 0 & $3(1.4)$ \\
Infusion related reaction (IRR) $)^{\star}$ & $33(20.5)$ & $12(7.9)$ & $13(21.7)$ & $25(11.8)$ \\
Malignancy & 0 & $2(1.3)$ & $1(1.7)$ & $3(1.4)$ \\
Progressive multifocal & & & & 0 \\
\multicolumn{1}{l}{ leukoencephalopathy } & 0 & 0 & 0 & \\
\hline
\end{tabular}

${ }^{*}$ None of IRR were serious or led to study drug discontinuation. 